\section{Acute transformation of a myeloproliferative state in sideroblastic anaemia with abnormal karyotype}

Recent data suggest that the incidence of leukaemic transformation in idiopathic refractory sideroblastic anaemia (IRSA) is lower than that given by Dameshek, and figures of 10 to $25 \%$ have been reported. ${ }^{12}$ We have recently followed the course of a patient with IRSA and a deletion in the long arm of chromosome 11, who developed a myeloproliferative syndrome transforming into acute myeloid leukaemia, a phenomenon which, to our knowledge, has not been observed before.

A 56-year-old garage owner presented with anaemia in 1965 and was diagnosed as having idiopathic refractory sideroblastic anaemia. In the period up to September 1979 his Hb fluctuated between 9.9 and $12 \mathrm{~g} / \mathrm{dl}$, WBC between 10 and $12 \times 10^{9} / 1$, with slight neutrophilia and mild eosinophilia. In October 1979 he was admitted with a 6-week history of mild dyspnoea. Bilateral basal crepitations were heard in the chest. There was no hepatosplenomegaly. FBC showed $\mathrm{Hb} 10 \mathrm{~g} / \mathrm{dl}$, WBC $17 \times 10^{9} / 1$ (neutrophils $73 \%$, lymphocytes $13 \%$, monocytes $8 \%$, myelocytes $6 \%$ ). The platelet count was raised to $596 \times$ $10^{9} / 1$. Chest $x$-ray showed right middle lobe consolidation which cleared with antibiotics but bilateral reticular shadowing throughout the lung fields persisted. Investigations carried out to ascertain the cause of the reticular pulmonary shadowing were consistent with the diagnosis of idiopathic pulmonary fibrosis. His clinical state improved after antibiotics and he was discharged from hospital.

In December 1979 he was noticed to be very pale. The FBC showed $\mathrm{Hb} 5.7 \mathrm{~g} / \mathrm{dl}$, WBC $25.8 \times 10^{9} / 1$, platelets $323 \times 10^{9} / 1$. Occasional blasts were seen on the peripheral blood film; the bone marrow was hypercellular, erythropoiesis was hyperplastic and grossly dyserythropoietic. Myelopoiesis was also hyperplastic and the numbers of megakaryocytes were increased. The myeloid/erythroid ratio was $5: 1$. Of the erythroid precursors, $85 \%$ were ring sideroblasts. He was transfused with six units of blood. The bone marrow picture in December 1980 showed markedly hyperplastic myelopoiesis with predominant myelocytes. Metamyelocytes and neutrophils, eosinophilic precursors, were prominent. Erythropoiesis remained unchanged; the myeloid/erythroid ratio was $20: 1$. Chromosomal analysis done from the marrow cells showed only one aberration: a deletion of the long arm of chromosome $11(\mathrm{q} 14 \rightarrow \mathrm{qter})$ in all the 20 cells analysed (figure).

In April 1981 the spleen, which had gradually been enlarging since December 1980, was palpable $16 \mathrm{~cm}$

Received for publication 13 April 1982. below the costal margin and there was a $5 \mathrm{~cm}$ hepatomegaly. The $\mathrm{Hb}$ was $7.5 \mathrm{~g} / \mathrm{dl}$, WBC $123 \times 10^{9} / 1$ (neutrophils $47 \%$, lymphocytes $8 \%$, monocytes $7 \%$, eosinophils $4 \%$, myelocytes $17 \%$, promyelocytes $4 \%$, blasts $13 \%$ ), nucleated red blood cells $2 / 100 \mathrm{WBC}$, platelets $119 \times 10^{9} / \mathrm{l}$. The film showed occasional giant platelets. Leucocyte alkaline phosphatase score was zero on two occasions, $B_{12}$ was $1400 \mathrm{ng} / \mathrm{ml}$ (normal 150-900), ferritin was $1000 \mathrm{ng} / \mathrm{ml}$ (normal 15-350), and $\mathrm{Hb} \mathrm{A}_{2}$ and $\mathrm{F}$ levels were normal. Heinz body preparation was negative. Bone marrow appearances and the chromosomal picture of the 30 cells analysed remained unchanged. He was treated with hydroxyurea $2 \mathrm{~g}$ daily.

In August 1981 he was admitted with history of anorexia and ulcers in the mouth. On examination the liver and spleen were enlarged $5 \mathrm{~cm}$ and $18 \mathrm{~cm}$ respectively below the costal margin. The FBC showed $\mathrm{Hb} 6 \cdot 5 \mathrm{~g} / \mathrm{dl}$, WBC $234 \times 10^{9} / 1$, platelets $27 \times 10^{9} / 1$, and the film showed $57 \%$ blasts, some with Auer rods. The blast cells were strongly positive with Sudan black and negative for PAS, c-ALL, and TdT. He died a week after admission of septicaemia.

The course of this patient's illness was unique. Between December 1979 and April 1981 a previously impalpable spleen enlarged to $16 \mathrm{~cm}$ below the costal margin and the WBC rose from $25.8 \times 10^{9} / 1$ to $123 \times 10^{9} / 1$. In December 1979 the bone marrow showed features suggestive of a myeloproliferative disease and these changes became established a year later. The ring sideroblasts and the abnormal chromosome 11 persisted throughout. This chromosomal abnormality has been found in association with acute monoblastic leukaemia and in other disorders including lymphoma, polycythaemia rubra vera, and pancytopenia $^{3}$ but, to our knowledge, has not been previously reported in IRSA. In view of the fact that all the metaphases examined showed this abnormality at a time when the features of IRSA and myeloproliferative state were both present, it is likely that these were different features of the same disease process.

Ghulam J Mufti, Terry J Hamblin, AND Marina SeAbright

Royal Victoria Hospital, Boscombe, Bournemouth; and Salisbury Infirmary, Fisherton Street, Salisbury.

\section{References}

1 Dameshek W. Sideroblastic anaemia. Is it a malignancy? Br J Haematol 1965; 11 :52-8.

${ }^{2}$ Levy RI, Kansu E, Gabuzda T. Leukemia in patients with acquired idiopathic sideroblastic anemia. An evaluation of prognosis indicators. Am J Hematol 1979;6:323-31.

3 Sandberg AA. The chromosomes in human cancer and leukaemia. Amsterdam: Elsevier/North Holland, 1980.

Requests for reprints to Dr Marina Seabright, Wessex Regional Cytogenetics Unit, The General Hospital, Salisbury, Wiltshire SP2 7SX. 